\title{
CORAK BUDAYA PATRIARKI DALAM PERKEMBANGAN \\ ILMU DAN TEKNOLOGI: \\ PERSPEKTIF EKOFEMINISME VANDANA SHIVA
}

Oleh

\author{
Krisna Suksma Yogiswari \\ Mahasiswa S3 UGM
}

Email: yogiswarikrisna@gmail.com

\begin{abstract}
This discussion aims to see the pattern of patriarchal culture taking part in the development of science and technology. This then creates a different space for women and men, especially in the development of science and technology in Asian countries. This discussion tries to see the current pattern of development of science and technology through the ecofeminism point of view of Vandana Shiva. The results of the analysis prove that the tendency of the pattern of development of science and technology today cannot be denied, many get influence from the West. That the progress of science and technology is so rapid as if it wants to match the development of the Western world, not necessarily in accordance with the character of Indonesianness and the character of Asian society
\end{abstract}

Keywords: Science, Technology, Women

\section{A. Pendahuluan}

Manusia sebagai makhluk berakal yang memiliki daya kreativitas serta kemampuan berpikirguna mengembangkan potensinya.Beberapabentuk dari pengembangan potensi manusia dapat berupa ilmu dan pengetahuan yang menghasilkan kemanfaatan praktis bagi kehidupan manusia. Ilmu dan pengetahuan sebagaimana berkembang begitu pesat telah memberikan sejumlah dampak baik positif maupun negatif. Dampak positif tentu mudah terlihat secara kasat mata yakni manusia semakin mudah mengakses keperluan untuk beraktivitas, pekerjaan manusia semakin ringan dengan adanya teknologi. Akan tetapi di samping dampak positif, ada juga dampak negatif yang mengikuti. Manusia dapat terlena oleh berbagai fasilitas yang ada pada teknologi, sehingga berpeluang mendegradasi potensi manusia itu sendiri.

Bicara mengenai potensi manusia apabila ditelaah lebih lanjut secara kritis, menunjukkan adanya pembedaan ruang lingkup antara perempuan dengan laki-laki. Hal tersebut sebagaimana dapat dipahami bahwa dalam aktivitas keilmuan serta teknologi terlihat lebih "bersahabat"bagi kaum laki-laki dibandingkan kaum perempuan. Ada kecenderungan bahwa ilmu dan teknologi bersifat patriarki seperti halnya penggunaan alat teknologi zaman modern yang penggunaannya hanya memenuhi standar keamanan bagi laki-laki atau hanya boleh digunakan oleh laki-laki. Perempuan pada situasi yang sama cenderung pasif, hanya melakukan 
pekerjaan ringan dan kurang berperan penting.

Persoalan demikian membuat sejumlah tokoh ataupun ilmuwan dalam bidang sosial ingin lebih lanjut mengkaji permasalahan atas kecenderungan pembedaan ruang lingkup keilmuan dan teknologi berkaitan dengan peran serta posisi laki-laki ataupun perempuan di tengah masyarakat global. Vandana Shiva merupakan filsuf India yang fokus mengkaji persoalan tersebut. Shiva memiliki ketertarikan akan masalah feminisme dan lingkungan yang kemudian memunculkan sebuah teori ekofeminisme. Shiva berpandangan bahwa kemajuan ilmu dan teknologi secara global cenderung didominasi oleh kelompok laki-laki yakni budaya patriarki. Shiva memahami situasi dan kondisi demikian sebagai satu bentuk penindasan bagi perempuan dan lingkungan.

Ekofeminisme merupakan sebuah gerakan yang muncul di kalangan perempuan di berbagai belahan dunia dari berbagai profesi sebagai akibat adanya ketidak adilan terhadap perempuan yang selalu dimitoskan dengan alam. Tulisan ini mengemukakan berbagai contoh peran perempuan dalam lingkungan hidup di berbagai negara. Pembahasan tentang lingkungan juga terkait dengan ekofeminisme sebagai implikasi kesadaran feminis yang tinggi di kalangan ilmuwan perempuan di perguruan tinggi di berbagai belahan dunia. Kesadaran para perempuan feminis terhadap eksploitasi alam membuat mereka bangkit berperan dalam penyelamatan lingkungan hidup sehingga tercipta kehidupan yang eco- friendly dan Womenfriendly. Kunci dari hal itu adalah melibatkan dan empati terhadap perempuan dalam perannya pada lingkup lingkungan hidup (Astuti, 2012: 49).

Perempuan diandaikan sebagai alam yang semestinya diperlakukan secara lembut. Perempuan sebagai makhluk Tuhan yang dikarunia rahim untuk melahirkan generasi manusia dipandang seperti halnya alam yang senantiasa melahirkan kemanfaatan untuk kehidupan manusia di bumi. Bertolak dari tesis tersebut, Vandana Shiva memunculkan konsep ekofeminisme yang bercorak Timur. Hal demikian sesuai dengan latar belakang Shiva yang berasal dari India, sehingga pemikirannya pun tidak terlepas dari nuansa Timur. Shiva memandang persoalan feminisme dan ekologi yang sedemikian pesat dimotori oleh Barat, menggunakan perspektif ekofeminisme bercorak ketimuran.

Penelitian ini nantinya akan berfokus pada tiga masalah utama yang selanjutnya akan dijawab dalam pembahasan yang dirumuskan sebagai berikut; (1) Bagaimana teori Ekofeminisme Vandana Shiva? (2) Bagaimana kecenderungan pola perkembangan ilmu dan teknologi masa kini? (3) Apa kontribusi pemikiran Vandana Shiva bagi masyarakat di negara wilayah Asia? Penelitian ini merupakan penelitian kualitatif dengan objek material perkembangan Ilmu dan Teknologi dengan perspektif Vandana Shiva sebagai objek formal.

Penulis mengangkat tema Perkembangan Ilmu dan Teknologi Ditinjau dari Perspektif Ekofeminisme Vandana Shiva dikarenakan teori Vandana Shiva berkaitan dengan persoalan aktual 
wanita, lingkungan, dan ilmu yang sering memicu diskusi guna melahirkan gagasan baru. Garis besar pemikiran Vandana Shiva menunjukan bahwa modernitas dan globalisasi yang dipelopori oleh negara bagian Barat mampu membawa pengaruh hingga ke negara di wilayah Asia yang dikenal memiliki nilai-nilai tradisional.

\section{B. Pembahasan}

\section{Teori Ekofeminisme Vandana Shiva}

Vandana Shiva lahir di Dehradun, Uttarakhand, India pada 5 November 1952 dan sekarang tinggal di New Delhi. Shiva adalah seorang filsuf, aktivis lingkungan, penulis buku, dan penulis makalah. Shiva juga berperan penting dalam gerakan ekofeminis global. Shiva menerima gelar Ph.D pada jurusan filsafat University of Western Ontario, Kanada. Shiva beranggapan bahwa ilmu zaman modern adalah proyek patriarki karena ilmu pengetahuan didominasi oleh peran kelompok tertentu yang mayoritas terdiri dari laki-laki kulit putih kelas menengah. Bagi penemu ilmu pengetahuan modern, ketergantungan pada bahasa gender tampak jelas.

Vandana Shiva
pembangunan menimbulkan mitos yang menempatkan warganya pada kondisi tidak adil. Pembangunan yang dipraktikkan negara Barat selalu menggunakan kekerasan psikis, ekonomi, dan fisik. Pandangan Shiva tersebut bukan tanpa alasan karena pembangunan yang dilakukan manusia saat ini mengakibatkan kerusakkan lingkungan seperti pembangunan ekonomi, dibutuhkan industrialisasi guna membangun ekonomi suatu negara. Pembangunan industri tersebut apabila tidak dikelola dengan baik seperti dari segi lokasi, jenis barang produksi ataupun dampak lingkungan yang diakibatkan maka berisiko merusak lingkungan.

Shivajuga mengajarkan ekofeminisme yaitu varian yang relatif baru dari etika ekologis atau etika lingkungan. Istilah ekofeminisme sendiri muncul pertama kali pada tahun 1974 oleh seorang feminis Perancis Francoise d'Eaubonne dalam bukunya Le Feminisme ou La Mort (Marks \& Courtivron, 1981). Francoise berupaya menggugah kesadaran manusia, khususnya kaum perempuan, akan potensi mereka untuk melakukan sebuah revolusi ekologis untuk menyelamatkan lingkungan hidup. Ekofeminisme menggabungkan kritik ekologi dengan kritik gender, dan menunjukan kritiknya kepada ilmu pengetahuan Barat yang berciri dualistik, cenderung didominasi teknologi dan buta gender. Para ekofeminis menyatakan bahwa dominasi atas alam adalah secara langsung berhubungan dengan faktorfaktor ekonomi, budaya, psikologi yang menciptakan hierarkhi, dan pada prakteknya menindas perempuan dan mengeksploitasi alam. Karakteristik dari ideologi-ideologi maskulin seperti misalnya; perang dan kekerasan, diskriminasi, pandangan etnosentrik, yang difasilitasi oleh teknologi dan ilmu pengetahuan Barat dilihat oleh kaum ekofeminis menjadi ancaman besar atas kesinambungan alam dan lingkungan (Plumwood 1993). Ekofeminisme merupakan teori yang melihat individu secara lebih komprehensif, sebagai mahluk 
terikat dan berinteraksi dengan lingkungannya. Pola pikir ini sejalan dengan ecophilosophy atau deep ecology yang mengajarkan kesatuan dari segala sesuatu. Para feminis yang dipengaruhi oleh pola pikir ini berpendapat bahwa perempuan secara intrinsik dianugerahi kapasitas merasakan keterikatan dirinya dengan alam. Sebenarnya, istilah ekofeminisme muncul pertama kali pada 1974 dalam buku Francoise d'Eaubonne yang berjudul Le Feminisme ou la mort (Rosemarie Putnam Tong, 2008: 46).

Pemikiran ekofeminismeVandana Shiva merupakan pendidikan lingkungan yang pada dasarnya berupaya menyadarkan manusia dengan memaparkan realita saat ini. Lingkungan alam sekitar berjalan dengan prinsip feminitas, sehingga apabila maskulintas menguasai alam maka akan terjadi kehancuran alam dan penindasan terhadap perempuan. Oleh karena itu, upaya memecahkan masalah hubungan gender dan menjaga lingkungan harus dilakukan melalui keterlibatan peran perempuan sebagai ibu, pengasuh, dan pemelihara dalam keluarga dan lingkungan dengan menggunakan prinsip feminitas yang ramah.

Ekofeminismeadalahsebuahgerakkan yang melihat hubungan antara eksploitasi dan degradasi alam dan subordinasi dan penindasan perempuan. Gerakkan tersebut muncul pada pertengahan 1970-an gelombang feminisme kedua dan gerakan hijau. Ekofeminisme menyatukan elemen gerakan feminis dan hijau, sementara pada waktu yang sama menawarkan sebuah tantangan untuk keduanya. Dibutuhkan gerakan guna mengatasi kekhawatiran atas dampak aktivitas manusia terhadap non-manusia di dunia dan dari feminisme pandangan kemanusiaan sebagai gender dalam cara yang subordinat, mengeksploitasi dan menindas perempuan (Mary Mellor, 1997: 1).

\section{Kecenderungan Masyarakat Global dalam Pola Perkembangan Ilmu dan Teknologi}

Ilmu modern adalah kegiatan yang secara sadar diberi muatan partriarki dan gender. Ketika alam semakin dilihat sebagai seorang perempuan yang perlu diperkosa. Genderpun diciptakan kembali. Ilmu sebagai upaya laki-laki didasarkan pada penundukan alam dan jenis kelamin perempuan meyediakan dukungan pada polarisasi gender (Vandana Shiva, 1997: 24). Shiva menentang kuasa ilmu modern yang mengembangkan pola teknologi bersifat kapitalistik. Pola tersebut juga bersifatreduksioniskarenamenyeragamkan keseluruhan pola keilmuan serta teknologi hingga memengaruhi negara dunia ke3. Barat mengajak negara dunia ke-3 termasuk negara di Asia agar turut menerapkan pola keilmuan dan teknologi Barat dengan dalih dapat memeroleh keuntungan secara instan dan mudah, padahal pola tersebut menghilangkan unsur lokal atau tradisionalitas yang memiliki nilai kedaerahan dalam menjaga alam dan perempuan. Masyarakat di wilayah Asia yang mengikuti pola keilmuan serta teknologi kapitalistik-patriarki menjadi kehilangan karakter kebangsaannya, karena menjadi tergantung pada pola keilmuan dan teknologi ala Barat.

Pemiskinan terhadap perempuan ini lebih banyak terjadi di negara-negara sedang berkembang yang menganut program 
pembangunan dan modernisasi Barat. Lebih lanjut lagi, perempuan-perempuan yang berada di pedesaan dan berhubungan langsung dengan kerja-kerja di alam seperti pertanian, perkebunan, perhutanan, dan lain sebagainya. Satu dari produk pembangunan adalah Revolusi Hijau dan Bioteknologi yang diperkenalkan melalui globalisasi lalu dicanangkan dan diadopsi oleh negaranegara sedang berkembang pada tahun 1990-an sehingga sekarang. Semestinya sejak program-program ini digalakkan, tujuan dikampanyekan program-program ini ialah untuk mensejahterakan masyarakat dunia dan memperkecil kemiskinan untuk membentuk Tata Dunia yang Baru (a New World Order) setelah Perang Dingin usai, tetapi ternyata program pembangunan ini membawa permasalahan yang masih dihadapi sehingga sekarang dengan semakin meluasnya pengadopsian paradigma neo-liberalisme bagi negaranegara sedang berkembang (Tyas Retno Wulan, 2007: 122).

Vandana Shiva menuding pendapat Francois Bacon mengenai "knowledge is power". Bacon menilai pengetahuan yang dianggap benar adalah pengetahuan yang sanggup menghasilkan keuntungan, memperbesar kemampuan dan kekuasaan manusia. Shiva menganggap hal tersebut sebagai tradisi epistemologi Barat yang membawa kekuatan patriarkis dan bersifat reduksionis. Hal ini disebabkan karena, tradisi pemikiran itu mengubah kemampuan manusia untuk mengetahui alam dengan menyingkirkan baik pelaku pengetahuan lain maupun cara-cara mengetahui yang lain. Tujuan dari jenis pengetahuan itu ketika diaplikasikan hanyalah menjalankan komersialisasi terhadap alam. Dalam hal ini, pembangunan sebagai syarat modernisasi lebih diarahkan merekayasa sesama manusia serta memperalat masyarakat untuk menaklukkan alam (Rosemarie Putnam Tong, 2008: 46).

Bila kita berbicara tentang ekofeminisme maka kita berbicara tentang adanya ketidakadilan di dalam masyarakat terhadap perempuan. Ketidakadilan terhadap perempuan dalam lingkungan ini berangkat pertama-tama dari pengertian adanya ketidakadilanyang dilakukan oleh manusia terhadapnon-manusia atau alam. Karena perempuanselalu dihubungkan dengan alammaka secara konseptual, simbolik dan linguistikada keterkaitan antara isu feminis danekologis. Menurut seorang ekofeminis,Karen J Warren (dalam Arivia, 2002) mengatakanbahwa keterkaitan tersebut tidakmengherankan mengingat bahwa masyarakatkita dibentuk oleh nilai, kepercayaan, pendidikan,tingkah laku yang memakai kerangkakerja patriarkhi, dimana ada justifikasihubungan dominasi dan subordinasi, penindasanterhadap perempuan oleh lakilaki.menurutnya, kerangka kerja tersebut berjalansebagai berikut: (1) cara berpikir dengan nilaihirarkhis, misalnya, "atasbawah", cara berpikir yang menempatkan nilai, prestise, statussebagai yang "atas" dan yang lainnya"bawah"; (2) nilai dualisme, misalnya bersikapoposisional (bukan saling melengkapi), ekslusif (bukan inklusif), status dan prestisemenjadi dasar dualisme ini, dualisme yangmemberikan nilai pada "akal", "rasio", "lakilaki"dan bukan pada "tubuh", "emosi", dan"perempuan"; dan (3) penekanan pada logikadan dominasi, misalnya, struktur argumentasiyang membenarkan subordinasi (Warren, 1996:51). 
Manusia dianggap sebagai penyebab menurunnya kualitas bumi karena berlebihan memuaskan nafsu duniawi tanpa mempedulikan akibat pada bumi. Kerusakan lingkungan disebabkan oleh mental dan nalar antroposentris yang tidak bersahabat dengan alam. Antroposentrisme yang merusak justru diagungkan epistemologinya oleh ilmu pengetahuan. Ilmu pengetahuan modern ialah kabar buruk dari ideologi patriarkal barat. Eksploitasi alam yang dilakukan oleh manusia selama ini tidak beraturan. Semakin banyak kekayaan alam yang dimiliki oleh suatu negara, semakin rusak kondisi alam negara tersebut. Ilmu pengetahuan yang diciptakan dimaksudkan untuk kepentingan serakah manusia dengan memanfaatkan isi alam sebanyak-banyaknya. Ilmu pengetahuan modern yang dibawa oleh barat adalah untuk kemajuan dan kepentingan manusia tanpa memerhatikan efek yang ditimbulkan terhadap alam (Shiva, xxiv-xxvi).

\section{Wujud Konkret Ekofeminisme Vandana Shiva dalam Konteks Kultur Lokal MasyarakatAsia}

Ekofeminisme ialah pandangan yang mendasarkan dari dua pemikiran penting ekologi dan feminisme, oleh karena itu pandangan ini dikenal sebagai "the ecology of feminism and the feminism of ecology" yang menawarkan jalan keluar masalah kehidupan manusia dan alam (Shiva, 1997: xviii). Manakala ekologi berasal dari bahasa Yunani yang dipopulerkan oleh Ernst Haeckel seorang biologis jerman pada tahun 1860-an, "oikos" yang berarti rumahtempat tinggal semua makhluk hidup dan "logos" berarti ilmu. Ekologi tersebut mempelajari hubungan antara manusia dan lingkungan hidup, mengaitkan ilmu kemanusiaan dan ilmu alam dan melihat dunia secara integral-holistik. Sedangkan intisari dari feminisme sendiri adalah suatu pandangan atau pemikiran yang berangkat dari kesadaran dan kepedulian terhadap segala bentuk penindasan, ketidakadilan, diskriminasi dan marginalisasi pada perempuan. Sedangkan perbedaan dalam cara mengidentifikasi isu-isu perempuan tersebutlah yang kemudian memunculkan beragam aliran dan pendekatan dalam feminisme; Marxist, Sosialis, Liberal, Radikal, Post-Modernis (Macey, 2000: 122). Gerakan feminisme dan ekologis mempunyai hubungan yang berkaitan terutamanya ketika berhadapan dengan logika kapitalis-patriarkhi. Adalah ketika pola dominasi terhadap alam dan terhadap perempuan menimbulkan kehancuran ekologis karena praktek dari pembangunan yang buta gender dan tidak ramah terhadap lingkungan.

Tokoh-tokoh dan pemikir ekofeminis:alam, budaya dan perempuan, bersepakat bahwa tradisi dan nilai-nilai perempuan dianggap mempunyai nilai-nilai lebih sehingga model lingkungan hidup yang mengadaptasi nilainilai feminis akan lebih baik bagi sistem lingkungan hidup secara keseluruhan.Beberapa uraian dan contoh-contoh diatas terlihat jelas peran perempuan dalam pengelolaan lingkungan juga penyelamatan lingkungan. Terlihat juga bagaimana polapikir, budaya dan kedekatan secara fisik danemosional antara perempuan dengan lingkungan.Oleh karena itu pada tataran lokaltertentu 
desa, kampung, kota (secara administratif, karena ada makna nonadministratifyang terkait dengan pola pikir, sikap, tindakan,kondisi) dapat mengadopsi beberapa yang sudah dijadikan contoh di atas. Adopsibukan berarti meniru sama persis, akan tetapimengambil ide-ide dasar dari para perempuaneko feminis dalam penyelamatan lingkungan,sudah sangat membantu dan bermanfaat. Kebanyakan orang selalu mengkaitkan dengan kearifan lokal ketika berbicara tentanglingkungan atau penyelamatan lingkungan.Hal ini dapat dipahami, karena usahausaha penyelamatan lingkungan selalu berkaitan dengan masyarakat adat, pendudukasli, masyarakat lokal, dimana merekalah yang memiliki cara-cara sesuai dengan adatkebiasaan dan budayanya dalam usaha penyelamatan lingkungan. Banyak kasus yang terdengar dan terlihat keberhasilannya ketikakita melibatkan kearifan lokal masyarakat setempat. Akan tetapi perkembangan selanjutnyakarena kepentingan global dan kemajuan jaman terkadang kearifan lokal justrubertentangan dengan usaha-usaha konservas ilingkungan atau penyelamatan lingkungan (Astuti, 2012: 58).

Menurut Strong (1995) kunci untuk memperbaiki bumi terletak pada penghormatan terhadap hukum alam yang dipahami oleh masyarakat asli tradisional. Masyarakat ini berbicara dengan kumpulan instruksi yangasli yang diberikan kepada mereka oleh Sang Pencipta. Mereka mengetahuinya dan menghidupi hukum ini, yang menuntun relasimanusia dengan empat elemen pemberi kehidupan,yakni, tanah, air, udara, dan api, serta mengajarkan penghormatan kepada kesatuan dan kesinambungan dari seluruh kehidupan. "Tidak ada jalan lain untuk perdamaian kecuali semua orang harus meninggalkan gerbang istana persepsi yang relatif, turun ke padang rumput, dan kembalike jantung alam yang non-aktif. Marilah kita katakan bahwa kunci perdamaian terletak dekat di bumi"(Astuti, 2012: 72).

Pandangan Shiva yang cenderung ke arah dimensi spiritual dapat diterapkan oleh bangsa Indonesia karena pada dasarnya sifat bangsa Indonesia yang spiritualistik dipengaruhi oleh kuatnya jiwa budaya peradaban masa lampau. Dominasi prinsip maskuilinitas yang terjadi di Indonesia menggambarkan pemikiran Shiva yang berangkat dari kepedulianya terhadap proses penghancuran ekologi akibat dari prinsip maskulinitas masih relatif dapat diterapkan dalam menjaga ekologi.

Seperti yang dinyatakan tokoh ekofeminis terkenal India Vandana Shiva, bahwa menurut beliau, visi baru mengenai masyarakat non-eksploitatif, masyarakat non-patriarkhi yang menghormati dan bukan menghancurkan alam, ialah berasal dari gerakan akar rumput, baik yang ada di negara-negara sedang berkembang atau berkembang, untuk mempertahankan kehidupan. Di dalam gerakan semacam ini, Shiva menuturkan bahwa perempuanlah yang lebih banyak memahami bahwa perspektif subsistence merupakan satusatunya jaminan akan keberlangsungan hidup, dan bukan integrasi ke dalam sistem 
pembangunan industri (Shiva \& Mies, 2005: 353).

Konsep subsistence berasal dari bahasa Latin subsistere berarti:"bertahan, menghentikan, tetap melakukan, melawan, mundur ke belakang, mempertahankan keterbelakangan". Saat ini, kata tersebut memiliki makna "memungkinkan untuk bertahan (dengan) kebutuhan dasar (minimum) dalam kehidupan" atau "untuk eksis dan mempertahankan diri sendiri dengan kekuatan sendiri”. Dengan semakin meningkatnya kerusakan lingkungan, menjadi hal yang penting bahwa subsistence/produksi kehidupan ini dapat menunjukan jalan keluar dari berbagai kebuntuan terhadap sistem destruktif dari masyarakat industri, ekonomi pasar atau kapitalis-patriarkhi. Ciri-ciri mendasar dari perspektif subsistensi ini adalah; bahwa tujuan dari kegiatan ekonomi bukanlah untuk sekedar menghasilkan timbunan komoditasdanuang(upahataukeuntungan), kegiatan ekonomi ini didasarkan pada relasi yang non-eksploitatif terhadap alam dan tanpa diskriminasi terhadap perempuan atau masyarakat lemah, ada partisipasi akar rumput, membutuhkan sebuah pendekatan terhadap pemecahan persoalan yang multidimensional atau sinergis, menuntut paradigma baru dari ilmu teknologi dan pengetahuan, menuntut terciptanya kembali integrasi kebudayaan dan kerja, menolak privatisasi dan komersialisasi milik publik (Shiva \& Mies, 2005:327).

Hal demikian sebagaimana telah dipraktikkan di desa Beji yang mengupayakan pelestarian serta perlindungan ekologi di hutan Wonosadi kabupaten Gunung Kidul. Praktik tersebut dapat dilakukan oleh kelompok akademisi seperti melakukan kegiatan pengabdian masyarakat yang memberikan sosialisasi kepada masyarakat desa Beji sebagai sarana persuasi memberikan pemahaman terkait pentingnya pelestarian pohon dan keterlibatan perempuan di dalamnya. Pemahaman yang diberikan untuk masyarakat desa Beji menghasilkan wujud konkret yakni menanam bibit pohon dengan merangkul masyarakat secara keseluruhan tanpa memandang gender ataupun kelas sosial tertentu (Suliantoro, 2014: 289-291).

\section{Implementasi Pandangan Ekofeminisme Vandana Shiva di Indonesia}

Adapun bentuk nyata atau aplikatif dari teori ekofeminisme Vandana Shiva di Indonesia dapat diwujudkan melalui satu upaya sosial sejumlah pihak yang peduli pada lingkungan. Salah satu bentuk upaya sosial tersebutdapatdimotoriolehkelompok masyarakat tertentu yang memahami dasar, esensi, ataupun tujuan dari teori ekofeminisme Vandana Shiva. Akademisi merupakan satu kelompok masyarakat yang dinilai mampu serta memiliki amanah sosial dalam mengupayakan penerapan teori-teori di bidang ilmiah agar bermanfaat bagi masyarakat. Oleh sebab itu, kelompok akademisi dapat mengadakan pengabdian masyarakat yang memberikan sosialisasi secara persuasif berisi pengetahuan tentang pentingnya penerapan teori ekofeminisme Vandana Shiva demi menjaga kelestarian lingkungan.

Salah satu bentuk merealisasikan teori ekofeminisme Vandana Shiva 
di dalam masyarakat dapat dilakukan oleh tim akademisi bidang ilmu filsafat sebagaimana menjadi latar belakang pandangan ekofeminisme Vandana Shiva. Upaya demikian pun telah terealisasi dalam satu kegiatan pengabdian masyarakat masyarakat desa Beji, pengelolaan hutan Wonosidi Kulon Progo. Selain itu, Bernadus Wibowo Suliantorodalam disertasinyaberjudul Etika Ekofeminis Vandana Shiva dan Karen J. Warren Sebagai Landasan Untuk Merekonstruksi Etika Lingkungan di Indonesia, menguraikan analisis reflektif mengenai persoalan lingkungan. Bentuk konkret dari perwujudan teori ekofeminisme Vandana Shiva khususnya, terlihat pada kerangka dasar berpikir feminisme yang identik dengan alam desa Beji. Masyarakat desa Beji diajak memahami kerangka pikir dasar pandangan ekofeminisme Vandana Shiva guna melangsungkan kegiatan lebih lanjut di lapangan.

Implementasi di lapangan yakni dalam pengelolaan hutan Wonosidi terlihat pada kesetaraan antara laki-laki dengan perempuan yang sadar akan keharusan berpartisipasi menyelamatkan lingkungan dari kerusakan. Hal tersebut menunjukkan bahwa kerja sama masyarakat baik lakilaki maupun perempuan dibutuhkan guna menyelamatkan serta menjaga lingkungan dari ancaman kerusakan lebih parah. Pemikiran Vandana Shiva memberikan kritik terhadap setiap pemikiran dan moderenisasi dewasa ini, termasuk di Indonesia dengan perkembangan teknologi dan sifat positivistik yang cenderung merusak alam. Shiva memberikan sumbangan untuk bangsa Indonesia berupa kesadaran kritis terhadap sikap yang tidak mengindahkan kaidah moral yang saat ini dianggap lazim. Hal tersebut ditunjukkan dari contoh gerakkan lingkungan, melalui prinsip feminitas seorang perempuan, alam dijadikan sebagai objek agar merawat dan menjaga alam dari dominasi ilmu pengetahuan yang cenderung dekstruktif.

\section{Kesimpulan}

Teori ekofeminisme Vandana Shiva merupakan kerangka pikir berupa sebuah konsep yang menggabungkan serta memandang interkoneksi antara etika lingkungan dengan feminisme. Shiva berpandangan bahwa perempuan yang sering kali diibaratkan sebagai alam telah tersubordinasi oleh budaya patriarki. Perempuan sebagai makhluk Tuhan yang dikarunaipotensimelangsungkanketurunan memang dapat dipandang seperti alam yang memiliki potensi menghasilkan sumber daya alam bermanfaat bagi kehidupan, tetapi pada hakikatnya pemahaman demikian semestinya berorientasi positif. Oleh sebab itu, pembahasan ekofeminisme Vandana Shiva fokus pada persoalan penindasan alam yang identik dengan penindasan perempuan dalam budaya patriarki yang bertolak dari kesadaran moral akan dalih pembangunan bersifat kapitalistik-patriarki ala Barat.

Kecenderungan pola perkembangan ilmu dan teknologi masa kini tidak dapat dipungkiri, banyak mendapatkan pengaruh dari Barat. Masyarakat di negara wilayah Asia seperti Indonesia mengikuti pola keilmuan dan teknologi ala Barat pada 
sejumlah fungsi strategis kebijakan, contohnya institusi pendidikan, pola bercocok tanam, hingga gaya hidup. Hal tersebut dapat disebabkan oleh gencarnya pihak Barat mempromosikan serta menanamkan sugesti pada masyarakat Asia agar mengikuti pola pembangunan kapitalistik-patriarki yang seolah-olah menawarkan banyak keuntungan secara instan dan mudah. Beberapa lingkup masyarakat di wilayah Asia pun mengikuti pola perkembangan ilmu dan teknologi ala Barat entah dengan pertimbangan politik atau ekonomi, padahal pilihan tersebut justru semakin mendegradasi karakter lokal yang menjadi pertahanan dasar masyarakat Asia.

Kontribusi pemikiran Vandana Shiva bagi masyarakat di negara wilayah Asia seperti halnya Indonesia, yakni menyumbangkan suatu konsep yang dapat menjadi alternatif dalam membangun kesadaran moral masyarakat. Bahwa kemajuan ilmu dan teknologi yang begitu pesat seolah-olah ingin menyamai Barat, belum tentu sesuai dengan karakter keIndonesia-an dan karakter masyarakat Asia. Masyarakat Asia, khususnya Indonesia dapat menerapkan ajaran ekofeminisme Vandana Shiva secara konkret dalam ruang kemasyarakatan dengan upaya persuasi yang melibatkan peran perempuan dan laki-laki. Vandana Shiva melalui karyakaryanya terkait ekofeminisme secara implisit ataupun eksplisit ingin mengajak masyarakat Asia agar kembali menerapkan pola tradisional guna melindungi lingkungan dan perempuan.

\section{DAFTAR PUSTAKA}

Arivia, Gadis. 2002. "Ekofeminisme: Lingkungan Hidup Berurusan dengan Perampuan". Jurnal Perempuan No. 21.

Astuti, Tri Marhaeni Pudji. 2012. Ekofeminisme dan Peran Perempuan dalam Lingkungan. Indonesian Journal of Conservation Vol. 1 No. 1.

Isshiki, Yoshiko. 2000. "Eco-Feminism in the 21 "Century", dalam In God's Image, Vol. 19. No. 3.

Mellor, Mary. 1997. Feminisme dan Ekologi. New York: New York University Press.

Plumwood, Val. 1993. The Mastery of Nature. London: Routledge.

Shiva, Vandhana. 1989. Staying Alive: Women, Ecology and Development. London: Zed Books.

1997. Bebas Dari Pembangunan. Jakarta: Yayasan Obor Indonesia.

dan Maria Mies. 2005. Ecofeminism: Perspektif Gerakan Perempuan dan Lingkungan. Yogyakarta: IRE Press.

Suliantoro, Bernadus Wibowo. 2014. Etika Ekofeminis Vandana Shiva dan Karen J. Warren Sebagai Landasan Untuk Merekonstruksi Etika Lingkungan di Indonesia. Yogyakarta: Sekolah Pascasarjana Universitas Gadjah Mada. 
Tong, Rosemarie Putnam. 2008.

Feminist Thought; Pengantar

Paling Komprehensifkepada Arus Utama Pemikiran Feminis. Yogyakarta: Jalasutra.

Warren, K. J. 1996. Ecological Feminist Perspective. Blommingtoon: Indiana University Press. 